\title{
Magnetic resonance imaging in patients with atrial fibrillation before left atrial appendage closure after brain hemorrhage
}

\begin{abstract}
Background: Brain MRI may be helpful for selecting patients at higher risk of further bleeding Benoit $\mathrm{A}^{1}$, Rioufol $\mathrm{G}^{2}$, Ong $\mathrm{E}^{1}$, Mechtouff after a first hemorrhagic stroke in patients with atrial fibrillation treated by oral anticoagulants.Cho $\mathrm{T}^{1}$, Derex $\mathrm{L}^{1}$, Thibault $\mathrm{H}^{3}$, Berthezène $\mathrm{Y}^{4}$, MRI may detect imaging markers consistent with an increased risk of further bleeding that Ovize $\mathrm{M}^{3}$ and Nighoghossian $\mathrm{N}^{1 *}$ could improve patient selection for left atrial appendage closure (LAAC).

Method: We studied clinical and imaging data of patients with atrial fibrillation treated by oral ${ }^{1}$ Department of Neurology, Hospices Civils anticoagulants who experienced hemorrhagic stroke. MRI was performed for the detection of Lyon, University Lyon 1, France small vessels disease abnormalities (cerebral amyloid angiopathy (AA) or severe hypertensive microangiopathy) suggesting a higher hemorrhagic risk thus supporting the choice of LAAC closure instead of anticoagulants to prevent thromboembolic events.

Results: Between December 2013 and February 2016, 37 patients were included. Among them 25 patients experienced brain hemorrhage and underwent a cerebral MRI before LAAC. $16 \%$ (4/25) had severe white matter damage, 24\% (6/25) exhibit MRI features consistent with hypertensive microangiopathy/or multiple cortical microbleeds (CMBs) and cortical superficial ${ }^{4}$ Department of Neuroradiology, Hospices siderosis (CSS) consistent with AA. 16\% (4/25) with mixed anomalies and 11 (44\%) had Civils de Lyon. University Lyon 1, France undetermined small vessel disease.

Conclusion: Brain MRI after a first hemorrhagic stroke may provide helpful information on the *Author for correspondence: risk of bleeding recurrence before LAAC.

Keywords: Magnetic resonance imaging; Atrial fibrillation; Left atrial appendage closure norbert.nighoghossian@chu-lyon.fr Tel: 330472357810
\end{abstract}

Fax: 330472357329

\section{Introduction}

In atrial fibrillation (AF), anticoagulation by vitamin $\mathrm{K}$ antagonists (VKA) or direct oral anticoagulants (DOA) reduces by $65 \%$ the risk of cerebral embolic events [1,2]. Although DOA trials showed a decreased incidence of fatal brain hemorrhage, several conditions (e.g. history of cerebral hemorrhage, large infarct size, severe leucoencephalopathy (LA), suspicion of cerebral amyloid angiopathy (CAA) may limit the resumption of anticoagulant treatments [3].

Left atrial appendage closure (LAAC) could be an acceptable alternative to anticoagulation in the prevention of brain embolism in patients with non valvular AF as suggested by several studies [4-9] especially in patients with recent hemorrhagic stroke in whom anticoagulation use may raise concern. Systemic bleeding risk is commonly assessed by the HAS BLED score [10]. However, Submitted: 06 May 2017 this scale does not take into account brain Accepted: 02 June 2017 imaging. Brain magnetic resonance imaging (MRI) may detect small vessels disease thus providing additional information to assess the risk of bleeding.

\section{Methods}

Patients

Between December 2013 and February 2016, 37 patients with nonvalvular AF and a high cardioembolic risk (CHA2DS2VASc scores >2) were included. Among them 25 patients underwent a cerebral MRI. Risk of hemorrhage was assessed by the HAS BLED score. Functional outcome was evaluated with the modified Rankin scale (mRS) at baseline and all follow-ups. Any serious adverse events (defined by: death, life-threatening event, requiring or prolonging hospitalization, or resulting in 
persistent or significant disability/incapacity) were recorded.

\section{Imaging protocol}

MRI was performed using $1.5 \mathrm{~T}$ clinical whole body unit with standard head coils. All patients underwent diffusion-weighted imaging (DWI), fluid-attenuatedinversion-recovery (FLAIR), T2-weighted gradient echo $\left(\mathrm{T} 2^{*}\right)$ and time of flight magnetic resonance angiography. Imaging data were independently reviewed by two experienced readers who were blinded to clinical history. MRI markers of small vessel disease were assessed as follows:

1. leucoencephalopathy was defined on FLAIR (or DWI $b=0$ images whenever FLAIR was unavailable) as hyperintense supratentorial white matter lesions. Leukoariosis was graded according to the Fazekas scale, both in periventricular $(0=$ absent, $1=$ caps or pencil lining, $2=$ smooth halo, and $3=$ irregular periventricular hyperintensities extending into deep white matter) and subcortical areas ( $0=$ absent, $1=$ punctuate foci, $2=$ beginning confluence of foci, and 3 =large confluent areas). The total Fazekas score was calculated by adding the periventricular and subcortical scores [11].

2. Cerebral microbleeds (CMBs) were defined as small perivascular hemosiderin deposits. $\mathrm{CMBs}$ appear as areas of signal void on $\mathrm{T}_{2}{ }^{*}$-weighted sequences. The location of CMBs was specified as either deep or lobar.

3. Cortical superficial siderosis (CSS) was defined as hypointense rims on the cortex in $\mathrm{T}^{*}$ images.

According to MRI findings, patients were divided into three categories: (Figure 1A) suspected AA according to the Boston criteria (Table 1, Figure 1B) [12] hypertensive microangiopathy and $\mathrm{C}$ ) undetermined small vessel disease.

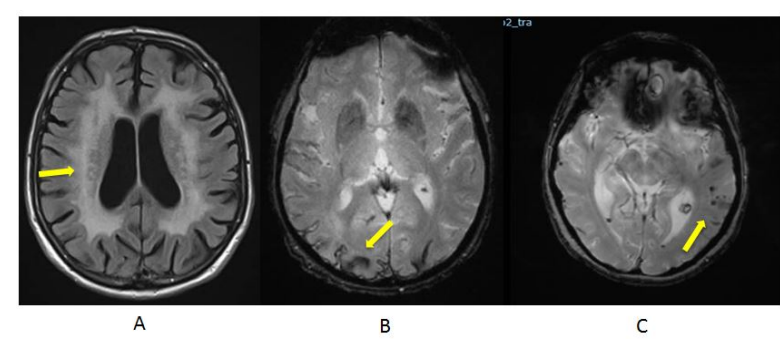

Figure 1: Patient 22 Suspected Amyloid Angiopathy A: MRI Flair sequence: severe leukoencephalopathy, B: MRI T2* Echogradient sequence: Superficial Siderosis C: Multiple lobar microbleeds.

\section{LAAC procedure and medications}

Echocardiographic criteria for LAA closure were an ejection fraction $\geq 30 \%$ and the absence of severe mitral regurgitation, mitral stenosis, or thrombus in the left atrium and/or LAA. Patients with large patent foramen ovale (PFO), defined as PFO with atrial septal aneurysms (total excursion $>15 \mathrm{~mm}$ or length $\geq 15$ $\mathrm{mm}$ ) or large shunts (substantial passage of bubbles within 3 beats) were excluded as well. Only patients whose LAA lengths were greater than their ostial diameters were closed with the Watchman LAA closure device. The procedure was performed under general anesthesia and three dimensional echocardiography guidance. Heparin was administered to a recommended active clotting time of 200s to 300s. The optimal compression grade was considered to range between $80 \%$ and $92 \%$. A trans-esophageal echocardiography (TEE) was performed at 3 and 12 months to assess device position, peri-device LAA flow, and device-related thrombus. Aspirin (100 mg/day) was started on the day before implantation and was combined to clopidogrel during one month, then continued until 6-months. This work did not require an ethics committee as patient management was considered as routine clinical practice but was conducted according to the World Medical Association Declaration of Helsinki - Ethical Principles for Medical Research Involving Human Subjects. All participants provided informed verbal consent or a legally authorized representative In the case of impaired comprehension of oral speech.

Table1: Boston Criteria for Diagnosis of Cerebral Amyloid Angiopathy-Related Hemorrhage

\begin{tabular}{|c|c|c|c|}
\hline Definite AA & $\begin{array}{l}\text { Probable AA } \\
\text { with } \\
\text { supporting } \\
\text { pathology }\end{array}$ & Probable AA & Possible AA \\
\hline $\begin{array}{l}\text { Full } \\
\text { postmortem } \\
\text { examination } \\
\text { demonstratin } \\
\mathrm{g} \text { : } \\
\text { - Lobar, } \\
\text { cortical, or } \\
\text { corticosubcor } \\
\text { tical } \\
\text { hemorrhage } \\
\text { - Severe CAA } \\
\text { with } \\
\text { vasculopathy } \\
\text { - Absence of } \\
\text { other } \\
\text { diagnostic } \\
\text { lesion }\end{array}$ & $\begin{array}{l}\text { Clinical data } \\
\text { and } \\
\text { pathologic } \\
\text { tissue } \\
\text { (evacuated } \\
\text { hematoma or } \\
\text { cortical } \\
\text { biopsy) } \\
\text { demonstratin } \\
\text { g: } \\
\text { - } \\
\text { cortical, or } \\
\text { corticosubcor } \\
\text { tical } \\
\text { hemorrhage } \\
\text { - Some } \\
\text { degree of } \\
\text { CAA specimen in } \\
\text { - Absence of } \\
\text { other diagnostic } \\
\text { lesion }\end{array}$ & $\begin{array}{l}\text { Clinical data } \\
\text { and MRI or CT } \\
\text { demonstratin } \\
\text { g: } \\
\text { - Multiple } \\
\text { hemorrhages } \\
\text { restricted to } \\
\text { lobar, cortical, } \\
\text { or } \\
\text { corticosubcor } \\
\text { tical regions } \\
\text { (cerebellar } \\
\text { hemorrhage } \\
\text { allowed) } \\
\text { - Age } \geq 55 \\
\text { years } \\
\text { - Absence of } \\
\text { other cause } \\
\text { of } \\
\text { hemorrhage }\end{array}$ & $\begin{array}{l}\text { Clinical data } \\
\text { and MRI or CT } \\
\text { demonstratin } \\
\text { g: } \\
\text { - Single lobar, } \\
\text { cortical, or } \\
\text { corticosubcor } \\
\text { tical } \\
\text { hemorrhage } \\
\text { - Age } \geq 55 \\
\text { years } \\
\text { - Absence of } \\
\text { other cause } \\
\text { of } \\
\text { hemorrhage }\end{array}$ \\
\hline
\end{tabular}

\section{Results}

The main indication of LAAC was a history of cerebral hemorrhage (20 patients: 6 patients had a lobar intracranial hemorrhage (ICH) and 12 patients had a deep ICH) and 2 had post-traumatic bleeding). MRI 
revealed that 16\%: (4/25) patients had severe white matter damage, 24\% (6/25) exhibit abnormalities consistent with hypertensive microangiopathy whereas $16 \%(4 / 25)$ had multiple cortical microbleeds (CMBs) and cortical superficial siderosis (CSS) consistent with AA and 11 (44\%) had mixed anomalies.
The baseline clinical characteristics and follow up of these 25 patients are summarized in Table 2 . The mean follow-up post-procedure was to 11.2 months \pm 6 . Ischemic stroke recurrence occurred in 3 patients out of 37 patients who underwent LAA (8\%).

\section{Table 2: Baseline clinical characteristics and follow up.}

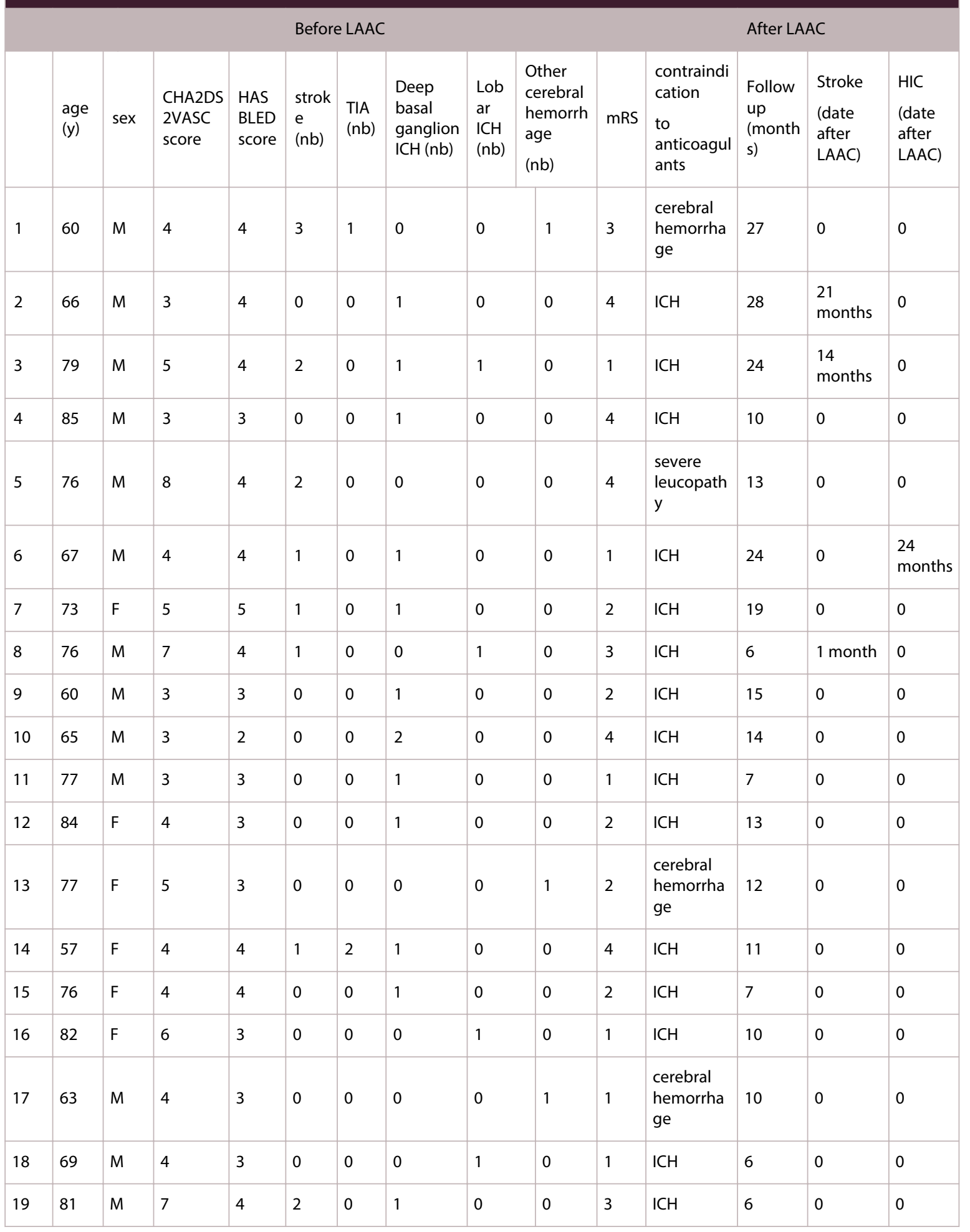




\begin{tabular}{|c|c|c|c|c|c|c|c|c|c|c|c|c|c|c|}
\hline 20 & 82 & $M$ & 6 & 3 & 2 & 0 & 0 & 0 & 0 & 2 & $\begin{array}{l}\text { Suspected } \\
\text { AA }\end{array}$ & 3 & 0 & 0 \\
\hline 21 & 73 & $\mathrm{~F}$ & 5 & 3 & 4 & 0 & 0 & 0 & 0 & 4 & $\begin{array}{l}\text { Suspected } \\
\text { AA }\end{array}$ & 3 & 0 & 0 \\
\hline 22 & 70 & $\mathrm{~F}$ & 5 & 3 & 1 & 0 & 0 & 0 & 0 & 4 & $\begin{array}{l}\text { hemorrha } \\
\text { gic } \\
\text { transform } \\
\text { ation of } \\
\text { infarct }\end{array}$ & 1 & 0 & 0 \\
\hline 23 & 81 & $\mathrm{~F}$ & 7 & 5 & 1 & 0 & 0 & 1 & 0 & 1 & $\begin{array}{l}\text { cerebral } \\
\text { hemorrha } \\
\text { ge }\end{array}$ & 3 & 0 & 0 \\
\hline 24 & 83 & $\mathrm{~F}$ & 6 & 4 & 0 & 0 & 0 & 2 & 0 & 1 & $\mathrm{ICH}$ & 3 & 0 & 0 \\
\hline 25 & 88 & $M$ & 7 & 4 & 2 & 0 & 0 & 0 & 0 & 2 & $\begin{array}{l}\text { hemorrha } \\
\text { gic } \\
\text { transform } \\
\text { ation of } \\
\text { infarct }\end{array}$ & 1 & 0 & 0 \\
\hline
\end{tabular}

ICH: Intracranial hemorrhage; TIA: Transient ischemic attack; mRS: modified Rankin scale

\section{Discussion}

Our study showed that MRI provides additional information on bleeding risk through the detection of markers of small vessels vulnerability which may further increase the risk of bleeding in patients treated with oral anticoagulants. Previous studies suggest that LAAC may be an alternative to anticoagulation among patients with AF [5-7]. However, most of these studies only included patients eligible for warfarin treatment, excluding patients with previous ICH. In this setting data are limited; a single study assessed the safety and feasibility of LAAC in patients with AF and previous ICH [13]. This study provided Class III evidence that in patients with a history of previous $\mathrm{ICH}$ and $\mathrm{AF}$, percutaneous LAAO is safe and feasible. No ischemic or hemorrhagic stroke occurred during a mean followup of 13.6 months. Conversely, in our study, with a similar follow up of 11 months, ischemic stroke occurred in three cases (11\%) and intracranial hemorrhage in one case. However due to the limited sample size no conclusion can be drawn concerning the risk/benefit of this procedure after brain hemorrhage.

There is a lack of evidence on the optimal prevention of ischemic stroke and other thrombo-embolic events in patients with non-valvular (AF) and recent $\mathrm{ICH}$ related to oral anticoagulants. However DOAs have not been tested in patients with $\mathrm{AF}$ and a recent $\mathrm{ICH}$. An ongoing trial: "Apixaban Versus Antiplatelet Drugs or no Antithrombotic Drugs after anticoagulationassociated Intracerebral Hemorrhage in patients with atrial fibrillation (APACHE-AF) ClinicalTrials.gov
NCT02565693 may provide helpful information in this setting.

Brain MRI before LAA may be helpful for selecting patients at higher risk of further bleeding after brain hemorrhage [14] as the presence of cerebral CMBs and severe LA are recognized as markers of bleeding risk [16-18].

The consensus view is that cortical CMBs tend to be manifestations of CAA, while deep hemispheric lesions are suggestive of hypertensive microangiopathy [18]. CAA-related $\mathrm{ICH}$ is classically diagnosed in adults over 55 years of age who had a lobar ICH and at least one other lobar CMBs or superficial siderosis and no other causative vascular or parenchymal pathologies. ICH related to hypertensive microangiopathy is seated in deep brain locations such as the basal ganglia, thalamus, or pons, mostly in patients who have a longstanding hypertension. The differentiation of these two most common types of $\mathrm{ICH}$ is very important in predicting the risk of recurrent ICH. Patients who suffer from CAA-related ICH have a 9-10\% annual risk of ICH recurrence, compared to a $-2 \%$ risk per year in survivors of deep ICH likely related to hypertensive microangiopathy [18].

CAA may be considered as a contraindication to anticoagulation before or after the occurrence of a lobar ICH but without obvious evidence from clinical trials [19]. However patients with suspected CAA on MRI are usually considered for LAAC. The situation is less clear in patients with hypertensive microangiopathy.

Although small vessels disease may promote further bleeding, additional prospective studies are required to delineate the role of MRI in guiding therapeutic 
decisions between oral anticoagulants and LAAC after brain hemorrhage.

Executive Summary

Background: Brain MRI may be helpful for selecting patients at higher risk of further bleeding after a first hemorrhagic stroke in patients with atrial fibrillation treated by oral anticoagulants. MRI may detect imaging markers consistent with an increased risk of further bleeding that could improve patient selection for left atrial appendage closure (LAAC).

Method: We studied clinical and imaging data of patients with atrial fibrillation treated by oral anticoagulants who experienced hemorrhagic stroke. MRI was performed for the detection of small vessels disease abnormalities (cerebral amyloid angiopathy (AA) or severe hypertensive microangiopathy) suggesting a higher hemorrhagic risk thus supporting the choice of LAAC closure instead of anticoagulants to prevent thromboembolic events.

Results: Between December 2013 and February 2016, 37 patients were included. Among them 25 patients experienced brain hemorrhage and underwent a cerebral MRI before LAAC. 16\% (4/25) had severe white matter damage, 24\% (6/25) exhibit MRI features consistent with hypertensive microangiopathy/or multiple cortical microbleeds (CMBs) and cortical superficial siderosis (CSS) consistent with AA. 16\% (4/25) with mixed anomalies and 11 (44\%) had undetermined small vessel disease.

Conclusion: Brain MRI after a first hemorrhagic stroke may provide helpful information on the risk of bleeding recurrence before LAAC.

\section{References}

1. Hart RG, Benavente O, McBride R, Pearce LA. Antithrombotic therapy to prevent stroke in patients with atrial fibrillation: a meta-analysis. Ann. Intern. Med. 7: 492501 (1999).

2. Ruff CT, Giugliano RP, Braunwald E, et al. Comparison of the efficacy and safety of new oral anticoagulants with warfarin in patients with atrial fibrillation: a meta-analysis of randomised trials. Lancet. 9921: 955-962 (2014).

3. O’Brien EC, Holmes DN, Ansell JE, et al. Physician practices regarding contraindications to oral anticoagulation in atrial fibrillation: findings from the Outcomes Registry for Better Informed Treatment of Atrial Fibrillation (ORBIT-AF) registry. Am. Heart. J. 167: 601-609 (2014).

4. Holmes DR. Atrial fibrillation and stroke management: present and future. Semin. Neurol. 30: 528-536 (2010).

5. Holmes DR, Reddy VY, Turi ZG, et al. PROTECT AF Investigators. Percutaneous closure of the left atrial appendage versus warfarin therapy for prevention of stroke in patients with atrial fibrillation: a randomised non-inferiority trial. Lancet. 9689: 534-542 (2009).

6. Belgaid DR, Khan Z, Zaidi M, Hobbs A. Prospective randomized evaluation of the watchman left atrial appendage closure device in patients with atrial fibrillation versus longterm warfarin therapy: The PREVAIL trial. Int. J. Cardiol. 219: 177-179 (2016).

7. Holmes DR, Doshi SK, Kar S, et al. Left atrial appendage closure as an alternative to warfarin for stroke prevention in atrial fibrillation: a patient-level meta-analysis. J. Am. Coll. Cardiol. 65: 2614-2623 (2015).

8. Reddy VY, Sievert H, Halperin J, et al. Percutaneous left atrial appendage closure vs warfarin for atrial fibrillation: a randomized clinical trial. JAMA. 312: 1988-1998 (2014).

9. Sharma D, Reddy VY, Sandri M, et al. Left Atrial Appendage Closure in Patients With Contraindications to Oral Anticoagulation. J. Am. Coll. Cardiol. 18: 2190-2192 (2016).

10. Pisters R, Lane DA, Nieuwlaat R, et al. A novel user-friendly score (HAS-BLED) to assess 1-year risk of major bleeding in patients with atrial fibrillation: the Euro Heart Survey. Chest. 5:1093-1100 (2010).

11. Fazekas F, Chawluk JB, Alavi A, Hurtig HI, Zimmerman RA. MR signal abnormalities at $1.5 \mathrm{~T}$ in Alzheimer's dementia and normal aging. AJR. Am. J. Roentgenol. 149: 351-356 (1987).
12. Knudsen KA, Rosand J, Karluk D, Greenberg SM. Clinical diagnosis of cerebral amyloid angiopathy: validation of the Boston criteria. Neurology. 56: 537-539 (2001).

13. Horstmann S, Zugck C, Krumsdorf U, et al. Left atrial appendage occlusion in atrial fibrillation after intracranial hemorrhage. Neurology. 82(2): 135-138 (2014).

14. Fisher M. MRI screening for chronic anticoagulation in atrial fibrillation. Front. Neurol. 4: 137 (2013).

15. Poels MM, Vernooij MW, Ikram MA, et al. Prevalence and risk factors of cerebral microbleeds: an update of the Rotterdam scan study. Stroke. 41: S103-S106 (2010).

16. Charidimou A, Boulouis G, Haley KE, et al. White matter hyperintensity pattern in cerebral amyloid angiopathy and hypertensive arteriopathy. Neurology. 6: 505-511 (2016).

17. Haley KE, Greenberg SM, Gurol ME. Cerebral microbleeds and macrobleeds: should they influence our recommendations for antithrombotic therapies? Curr. Cardiol. Rep. 12: 425 (2013).

18. Eckman MH, Rosand J, Knudsen KA, Singer DE, Greenberg SM. Can patients be anticoagulated after intracerebral hemorrhage? a decision analysis. Stroke. 7: 1710-1716 (2003) 